\title{
Methods of Biotyping of Streptococcus mutans Species with the Routine Test as a Prognostic Value in Early Childhood Caries
}

\author{
Wirginia Krzyściak, ${ }^{1}$ Dorota Kościelniak, ${ }^{2}$ Monika Papież, ${ }^{3}$ \\ Anna Jurczak, ${ }^{2}$ and Palina Vyhouskaya ${ }^{1}$ \\ ${ }^{1}$ Department of Medical Diagnostics, Faculty of Pharmacy, Jagiellonian University Medical College, Medyczna 9, \\ 30-688 Kraków, Poland \\ ${ }^{2}$ Department of Pediatric Dentistry, Institute of Dentistry, Jagiellonian University Medical College, Kraków, Poland \\ ${ }^{3}$ Department of Cytobiology, Faculty of Pharmacy, Jagiellonian University Medical College, Kraków, Poland
}

Correspondence should be addressed to Wirginia Krzyściak; wirginiakrzysciak@cm-uj.krakow.pl

Received 9 March 2017; Accepted 4 May 2017; Published 15 June 2017

Academic Editor: Filippo Fratini

Copyright (C) 2017 Wirginia Krzyściak et al. This is an open access article distributed under the Creative Commons Attribution License, which permits unrestricted use, distribution, and reproduction in any medium, provided the original work is properly cited.

Purpose. In order to investigate the suitability of Streptococcus mutans species biotyping by measuring the activity of selected enzymes from a commercial test, criteria were established for biotyping clinical strains from children with dental caries. In addition, the relationships between the selected biotypes, sensitivity to commonly used antibiotics, and early childhood caries were determined. Methods. A total of 142 S. mutans isolates from dental plaque of children with caries were divided into different biotypes. Patients were divided into two groups: noncavitated (1-2 in ICDAS) and cavitated (5-6 in ICDAS) lesions. Biotyping criteria were determined based on both the arbitrary method and the clusterization method. The susceptibility of the strains to amoxicillin, cefazolin, erythromycin, and teicoplanin was studied by diluting a solid medium. Results. Biotype I was the most common. Mean MIC values showed that the strains belonging to biotypes II and IV were the most sensitive to amoxicillin. For predetermined biotypes, observed differences were dependent on the severity of dental caries. Conclusions. The proposed method of $S$. mutans strains biotyping is relatively quick and simple to use, provided the application of suitable biotyping criteria, and may contribute to the effective prevention of dental caries induced by $S$. mutans.

\section{Introduction}

Dental caries is a chronic disease occurring widely in the human population and is the most common childhood disease. This is a multistage morbid process which, in addition to microbiological agents, also includes the susceptibility of host tissues to microbiological agents, the presence of carbohydrates in the oral cavity, and a sufficiently long duration of action of all these factors on the tooth enamel.

The microorganism Streptococcus mutans is considered one of the main etiological factors of dental caries. This commensal microorganism has a number of features that in appropriate environmental conditions determine its pathogenicity. Penetration of the physical and immunological protective host barriers by $S$. mutans leads to an invasion by the microorganism and consequent infection of the body. Most infections caused by $S$. mutans are a consequence of its proliferation in the human body. There are listed cases when S. mutans has induced endocarditis and bacteremia [1-3] or has been isolated from the heart valve of a patient with endocarditis [4]. Recurrent bacteremia in a woman with Sjögren's syndrome was also caused by this microorganism [5]. In addition to endocarditis and bacteremia, S. mutans may induce sepsis [6] or may be isolated from patients after ischemic stroke [7]. It is presumed that $S$. mutans can cause other systemic diseases [8]. A rare case of retroperitoneal abscess caused by $S$. mutans has also been described [9]. 
Adverse effects of the microorganism's activity may be reduced by using prophylaxis or by an effective immune response from the host. On the other hand, excessive host immune response may lead to self-destruction of the organism as a result of the protective role of the organism against the bacteria (own unpublished studies).

A thorough study of $S$. mutans biotypes is necessary to determine the differences in susceptibility to selected antibiotics and subsequent effective prevention of infection by this microorganism. Moreover, the correct classification of the $S$. mutans species in selected biotypes may shed new light on their exact origin and the incidence of various infections concomitant to caries, including bacteremia or ischemic stroke, making effective prevention by healthcare professionals easier to carry out.

There are various methods for typing $S$. mutans strains; one of the earliest introduced methods is agglutination-based serotyping [10] or typing based on auxonogram, which uses intraspecies differences in the ability to assimilate various organic compounds. Depending on the compounds used, there are different variations of this method. Quite popular in routine diagnostics is the typing of $S$. mutans strains upon auxonograms and enzymograms of STREPTOtest 24 (Lachema, Pliva) [11], as well as API 20 Strep (bioMérieux) [12].

Another typing method is biotyping based on selected reactions of commercial enzymatic tests. Biochemical typing may have similar usefulness in terms of the differentiation of group B streptococci as serotyping [13]. Biotyping is applicable to the streptococci of Streptococcus mutans group (S. mutans and S. sobrinus) isolated from dental plaque [14].

This article focuses on both the identification of the biotyping criteria for clinical $S$. mutans strains isolated from children with varying degrees of severity of dental caries and the assessment of the relationships between the selected biotypes in vitro, sensitivity to commonly used antibiotics, and severity of dental caries in children.

\section{Materials and Methods}

A total of 143 S. mutans strains were isolated from supragingival plaque (scraped from the tooth surface using a sterile dental excavator) of the molar milk teeth of children with early caries ( $n=143$; average age: $4.6 \pm 0.76$ years). Criteria for the examinations were in accordance with Oral Health Surveys Basic Data (World Health Organization) [15]. Examinations were conducted with the use of a dental mirror and a probe in artificial light. The ICDAS (International Caries Detection and Assessment System) was applied to classify the severity of tooth decay and its division into study groups (1: first changes in enamel visible "only after prolonged air drying or restricted to within the confines of a pit or fissure"; 2: distinct visual enamel changes, no loss of surface integrity; 3: localized enamel breakdown; 4: underlying dentin shadows; 5 : distinct cavities, visible dentin; 6: extensive distinct cavities, visible dentin) [16]. The daily oral hygiene of patients involved in the study comprised brushing teeth twice a day using a manual brush and a fluoride toothpaste. The exclusion criteria comprised age $<2$ or $>6$ years, diabetes, epithelial dysplasia, periodontal disease, inflammatory lesions of the oral mucosa, and use of antibiotics, nonsteroids, anti-inflammatory medications, corticosteroids, and vitamins within the last 3 months.

Patients were divided into two groups: a noncavitated group with initial tooth decay (ICDAS 1-2; $n=97$, average age: $4.64 \pm 0.77$ years, including 47 females aged $4.68 \pm 0.91$ years and 50 males aged $4.6 \pm 0.61$ years) and a cavitated group with extensive decay (ICDAS 5-6; $n=46$, average age: $4.52 \pm$ 0.75 years, including 20 females aged $4.75 \pm 0.85$ years and 26 males aged $4.35 \pm 0.63$ years). The division criterion between the two groups was the lack/presence of visible carious tissue loss.

Dental plaque was evaluated with the Simplified Oral Hygiene Index (OHI-S) which assesses its presence on 6 teeth of different groups $(55,53,51$ and $75,73,71)$, lingual surfaces of the mandibular teeth, and labial surfaces of the maxillary teeth ( 0 : lack of calculus; 1 : calculus covers $<1 / 3$ of the tooth surface; 2 : calculus covers $1 / 3-2 / 3$ of the surface; 3 : calculus covers $>2 / 3$ of the tooth surface) [17]. The OHI-S in all examined children was equal to 1 .

Before the examination, patients remained fasting and did not clean their teeth on the day of the study. Material was collected after rinsing the oral cavity with distilled water in the morning (before 11 a.m.). The collected plaque was placed in Eppendorf sterile tubes with $0.5 \mathrm{ml}$ of saline without access to atmosphere oxygen and transported to the laboratory on ice within $2 \mathrm{~h}$. Subsequently, the samples were sonicated for $20 \mathrm{~s}$ at an amplitude of $5 \mu \mathrm{m}$, vortexed to obtain a homogeneous suspension, and centrifuged at $1,000 \mathrm{~g}$ at a temperature of $4^{\circ} \mathrm{C}$ for $15 \mathrm{~min}$. A total of $100 \mu \mathrm{l}$ of the supernatant was used in conventional growth methods.

Levels of Streptococcus mutans in plaque were determined using selective agar. The plaque was inoculated on a HLR-S agar medium in the laboratory. It was assumed that the role of the medium consisted of support for the growth of the tested microorganisms and inhibition of the remaining species found in the saliva. The incubation time was $48 \mathrm{~h}$ under microaerophilic conditions $\left(85 \% \mathrm{~N}_{2}, 10 \% \mathrm{CO}_{2}\right.$, and $\left.5 \% \mathrm{O}_{2}\right)$ at $37^{\circ} \mathrm{C}$. The HLR-S medium was selected based on our previous study, where we had tested media described in the literature as being selective for specific bacterial species isolated directly from the oral cavity (from plaque or saliva samples) [18, 19].

Individual cultivated colonies were inoculated on the TSA medium with 5\% sheep blood and incubated for $24 \mathrm{~h}$ under the above conditions. Then, the morphological characteristics of individual colonies cultivated on the medium with sheep blood were evaluated, as was the type of hemolysis caused by these colonies. In addition, plaque was formed, and this was inoculated on the HLR-S medium. The colonies were counted via determination of CFU/ml (Figure 1). The number of microorganisms present in a particular test sample was determined using the formula

$$
\mathrm{CFU} / \mathrm{ml}=\mathrm{CF}
$$

Cultures of microorganisms were carried out under microaerophilic conditions and visualized with Gram staining under a light microscope, as well as under an electron microscope. 


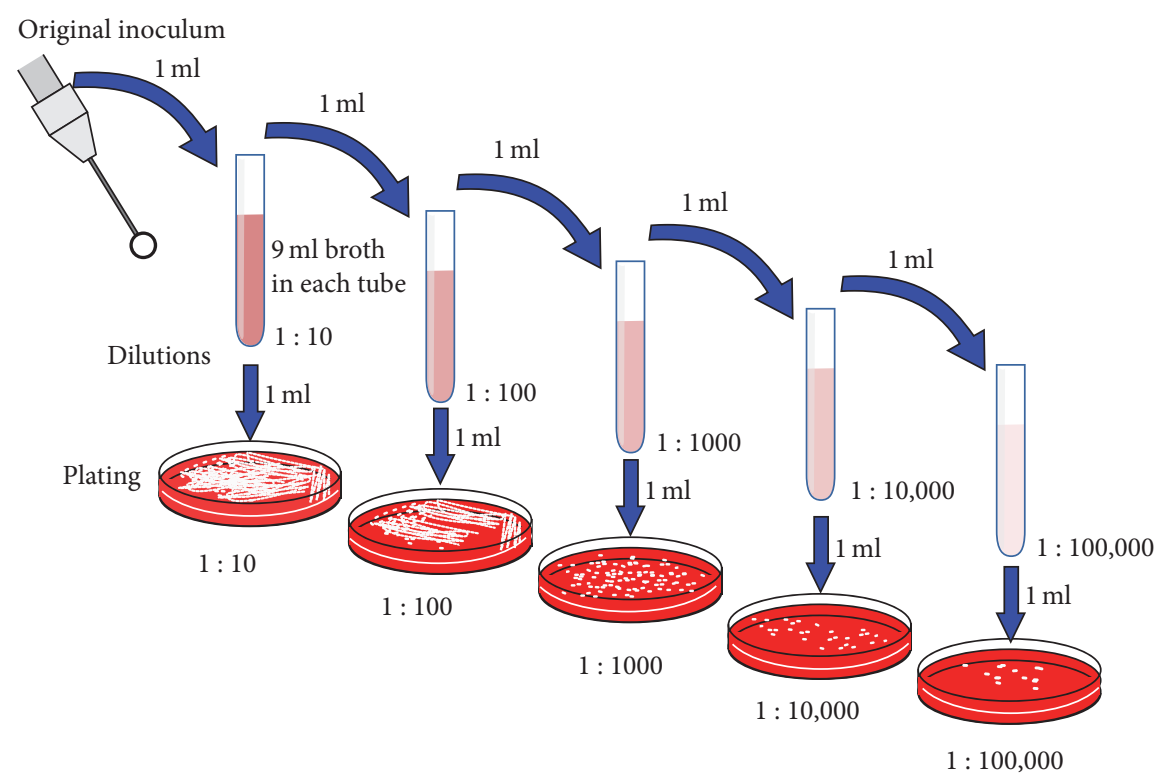

Figure 1: Preparations of the dilutions of bacterial suspension.

Phenotypic identification was performed using a commercially available assay for the streptococci identification (STREPTOtest 24, Lachema). The enzymes used in the study are given in Table 1. Isolated strains were cultured on HLR$S$ medium for two days under microaerophilic conditions. The single colonies of bacteria once grown were inoculated on blood agar (BA) and incubated for two days at $36^{\circ} \mathrm{C}, 5 \%$ $\mathrm{CO}_{2}$ conditions. A suspension of pure colonies was prepared in a $3-3.5 \mathrm{ml}$ sterile $\mathrm{NaCl}$ solution to obtain $2-2.2$ on the McFarland scale (Figure 2). A total of $100 \mu \mathrm{l}$ of this bacterial suspension was applied to each of the wells of the first row (designated as NAG, LAP, bMN, GLR, bGL, bGA, Aga, and PHS) and to wells in column $\mathrm{H}$ (designated as ESL and ARG). $1.5 \mathrm{ml}$ of the above suspension was transferred to a $\mathrm{NaCl}$ solution as a medium for the STREPTOtest 24 suspension (Lachema, Pliva). A total of $100 \mu \mathrm{l}$ of the thus prepared solution was applied to each of the remaining reaction wells (INU, MAN, SOR, MLB, RIB, LAC, PUL, S06, AMG, TGT, MLT, RAF, TRE, and SOE). A drop of paraffin oil was added to the plate wells designated as Arg and S06.

Following the transfer of the prepared solutions, the specimens were incubated for $24 \mathrm{~h}$ at $37^{\circ} \mathrm{C}$. The reading was based on a visual assessment with the comparative color scale supplied by the manufacturer. The results were interpreted as "positive" or "negative" and were represented on a 7-point scale (0-7) depending on the intensity of the color reaction (Figure 3). Species were identified based on the codebook provided by the manufacturer (the bacterial species are encoded).

Grouping of 143 identified S. mutans strains was performed based on the differences in the activity of selected enzymes from the commercial test used in diagnostics. Out of the 24 enzymes present in the STREPTOtest 24, those enzymes were selected for biotyping, whose occurrence among the tested strains was in the $15-85 \%$ quartile deviation,

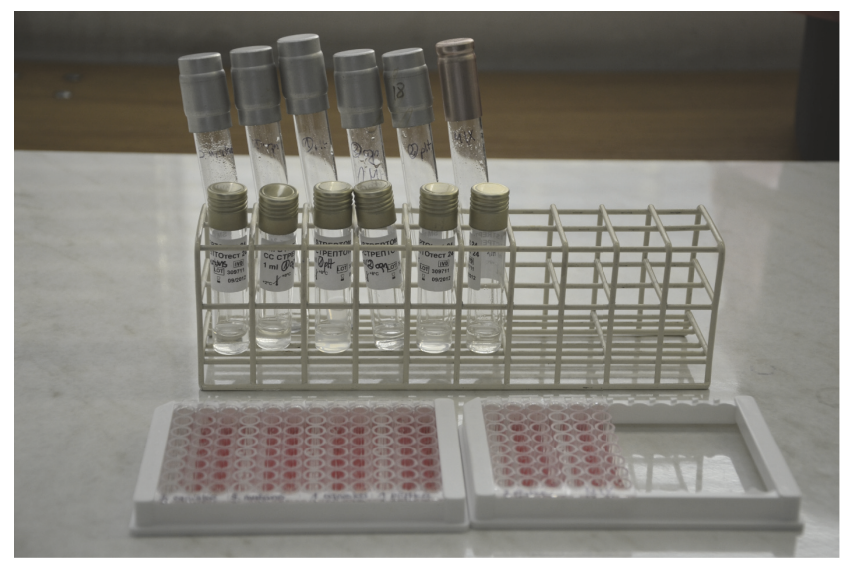

FIgUre 2: Prepared identification STREPTOtest 24 tests (Lachema, Pliva). In the stand, there are bacterial suspensions in saline, suspension media for STREPTOtest 24, and identification panels established in accordance with the manufacturer's instructions.

that is, inulin $(40.56 \%)$, melibiose $(83.22 \%)$, and tagatose (21.68\%) (Table 2).

The assay was performed in triplicate for each strain, and each set of tests was evaluated independently by a second observer. Subsequently, 143 strains were tested for sensitivity to the selected classes of antibiotics, including the $\beta$ lactams (amoxicillin, cefazolin), the macrolides (erythromycin), and the glycopeptide antibiotic (teicoplanin), using a dilution method in a solid phase in the concentration range $0.007-1.5 \mathrm{mg} / \mathrm{L}$ [20]. The statistical significance of differences in susceptibility to selected antibiotics in particular biotypes was determined using the Kruskal-Wallis test complemented by post hoc analysis (Dunn's test). 
TABLE 1: Enzymatic reaction panel contained in the STREPTOtest 24 (Lachema, Pliva).

\begin{tabular}{lcc}
\hline Code & Tested enzyme & Reaction \\
\hline NAG & N-Acetyl-glucosaminidase & Hydrolysis \\
LAP & L-Leucine-aminopeptidase & Hydrolysis \\
bMN & $\beta$-Mannosidase & Hydrolysis \\
GLR & $\beta$-Glucuronidase & Hydrolysis \\
bGL & $\beta$-Glucosidase & Hydrolysis \\
bGA & $\beta$-Galactosidase & Hydrolysis \\
Aga & $\alpha$-Galactosidase & Hydrolysis \\
PHS & Phosphatase & Compound hydrolysis \\
ESL & Esculin & Compound hydrolysis \\
INU & Inulin & Sugar fermentation \\
MAN & Mannitol & Compound fermentation \\
SOR & Sorbitol & Sugar fermentation \\
MLB & Melibiose & Sugar fermentation \\
RIB & Ribose & Sugar fermentation \\
LAC & Lactose & Sugar fermentation \\
PUL & Pullulan & Compound hydrolysis \\
ARG & Arginine & Hydrolysis \\
S06 & $\alpha$ Growth in $6.5 \%$ NaCl \\
AMG & $\alpha$-Methylglucosidase & Hydrontation \\
TGT & Tagatose & Sugar fermentation \\
MLT & Maltose & Sugar fermentation \\
RAF & Raffinose & Sugar fermentation \\
TRE & Trehalose & Sugar fermentation \\
SOE & Sorbose & Sugar fermentation \\
\hline
\end{tabular}

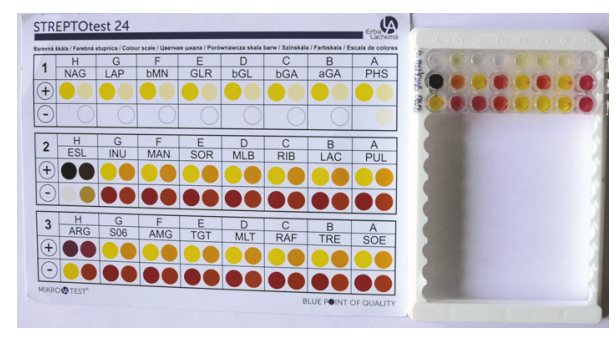

(a)

(b)

FIgURE 3: Comparative color scale (a) and STREPTOtest 24 identification test (Lachema, Pliva) after incubation (b). The test result was evaluated based on the color scale shown above.

In the clustering process, the following methods were used: hierarchical clustering, scree plot showing decrease in ESS (error sum of squares), and an objective method (silhouette).

\section{Results}

\subsection{Phenotypic Identification}

3.1.1. Morphological Characteristics. The isolated bacterial species were Gram-stained and viewed under a light microscope at an objective magnification of $40 \mathrm{x}$. The size of the observed colonies ranged from 0.5 to $1 \mu \mathrm{m}$. The spatial
TABLE 2: The prevalence of particular enzymes.

\begin{tabular}{lc}
\hline Enzyme & Prevalence \\
\hline NAG & $6.99 \%$ \\
LAP & $100.00 \%$ \\
bMN & $0.00 \%$ \\
GLR & $0.00 \%$ \\
bGL & $90.21 \%$ \\
bGA & $90.91 \%$ \\
aGA & $90.21 \%$ \\
PHS & $11.89 \%$ \\
ESL & $100.00 \%$ \\
INU & $40.56 \%$ \\
MAN & $100.00 \%$ \\
SOR & $90.91 \%$ \\
MLB & $83.22 \%$ \\
RIB & $11.89 \%$ \\
LAC & $100.00 \%$ \\
PUL & $0.00 \%$ \\
ARG & $0.00 \%$ \\
S06 & $0.00 \%$ \\
AMG & $0.00 \%$ \\
TGT & $21.68 \%$ \\
MLT & $86.01 \%$ \\
RAF & $86.01 \%$ \\
TRE & $100.00 \%$ \\
SOE & $0.00 \%$ \\
\hline
\end{tabular}

arrangement of cells resembled chains long as beads (Figure 4). The tested species of bacteria did not produce catalase. On a medium supplemented with sheep blood, they demonstrated $\gamma$-hemolysis (Figure 5).

Two approaches were used in determining biotypes among the 143 isolated S. mutans strains. The first approach was to select particular enzymes based on the analysis of their activity in the population of tested strains. Five enzymes present in all strains (reactions referenced as LAP, MAN, LAC, and TRE), the growth test in the presence of $6.5 \%$ $\mathrm{NaCl}$, which was negative for all strains, and seven enzymes that were not present in any strain (bMN, GLR, PUL, ARG, S06, AMG, and SOE) were not suitable for differentiation and were rejected per se. Another seven enzymes occurring in these cases were also rejected, because the use of these enzymes in biotyping would have resulted in a heterogeneous distribution of strains in particular biotypes (there would have been too many biotypes containing one strain): $\beta$-glucuronidase occurring in $90.21 \%$ of the strains, $\beta$ galactosidase $(90.91 \%), \alpha$-galactosidase $(90.21 \%)$, sorbitol (90.91\%), ribose $(11.89 \%)$, phosphatase $(11.88 \%)$, maltose (86.01\%), and raffinose (86.01\%).

When criteria for including enzymes into biotyping are narrowed to $10-90 \%, 7$ enzymes are left giving 24 profiles, or 12 biotypes. When the range $12.5-87.5 \%$ is considered, only 5 enzymes are left giving 18 profiles and 9 biotypes. When the $15-85 \%$ range is considered, 3 enzymes are obtained, giving 8 profiles (Table 3 ) and finally 4 biotypes (Table 4 ). 


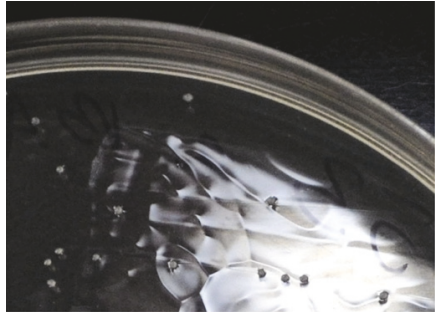

(a)

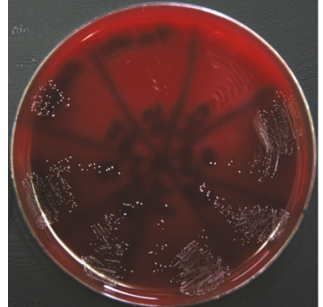

(b)

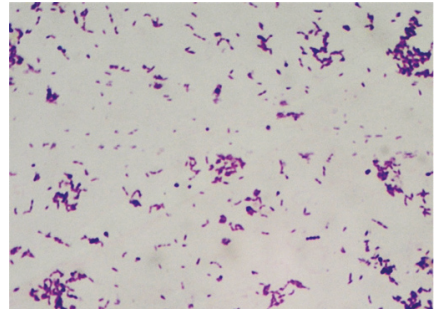

(c)

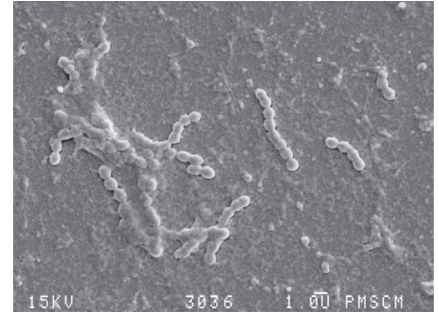

(d)

FIgURE 4: Streptococcus sp. cells isolated from dental plaque from a child with ECC. The picture shows the macro- and micromorphology of Streptococcus sp. (a) S. mutans colonies with a characteristic white color on the HLR-S selective medium; (b) on blood agar BA; (c) Gramstained S. mutans cells (Olympus CX41, CaMedia C5550); (d) S. mutans cells under a scanning electron microscope.

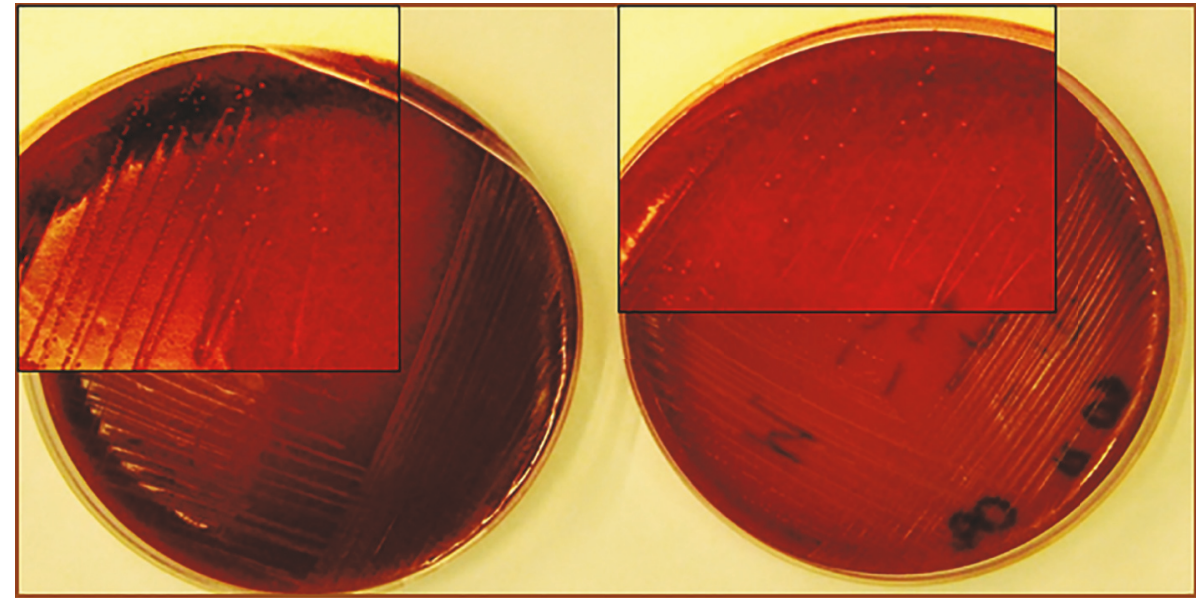

(a)

(b)

FIGURE 5: Macrophotography of the S. mutans species. (a) S. mutans standard strain ATCC 700610. (b) S. mutans strain isolated from the clinical material. Visible characteristic small white colonies and the absence of hemolysis on the blood substrate.

TABLE 3: Enzymatic profiles of S. mutans obtained based on the prevalence of activity of three enzymes: INU, MLB, and TGT in the STREPTOtest 24.

\begin{tabular}{lccccc}
\hline Enzymatic profile & INU & MLB & TGT & $n$ & Percentage \\
\hline A & - & - & - & 1 & $0.70 \%$ \\
B & - & - & + & 10 & $6.99 \%$ \\
C & - & + & - & 61 & $42.66 \%$ \\
D & - & + & + & 13 & $9.09 \%$ \\
E & + & - & - & 11 & $7.69 \%$ \\
F & + & - & + & 2 & $1.40 \%$ \\
G & + & + & - & 39 & $27.27 \%$ \\
H & + & + & + & 6 & $4.20 \%$ \\
\hline
\end{tabular}

We decided to choose the latter, because, given the 143 samples, even a biotype number equal to 9 would be too large (on average, this gives less than 16 samples per biotype).

Enzymes chosen for biotyping were INU, MLB, and TGT. The adoption of these enzymes as the biotyping criteria allowed the specification of 8 enzymatic profiles, conventionally defined with consecutive letters of the alphabet from $A$ to
TABLE 4: Four S. mutans biotypes obtained based on differences in the activity of inulin, melibiose, and tagatose in the STREPTOtest 24 .

\begin{tabular}{lccc}
\hline Biotype & Enzymatic profile & $n$ & Percentage \\
\hline I & $\mathrm{A}+\mathrm{C}$ & 62 & $43.36 \%$ \\
II & $\mathrm{B}+\mathrm{D}$ & 23 & $16.08 \%$ \\
III & $\mathrm{E}+\mathrm{G}$ & 50 & $34.97 \%$ \\
IV & $\mathrm{F}+\mathrm{H}$ & 8 & $5.59 \%$ \\
\hline
\end{tabular}

$\mathrm{H}$, as shown in the table (Table 3 ). Profile $\mathrm{C}$ characterized by a lack of activity of inulin and tagatose is the most numerous.

Resolution of the obtained profiles is heterogeneous, and therefore strains whose profiles differ only in MLB (MLB is the nearest to being excluded from the $15-85 \%$ range) were grouped into one biotype. The four such biotypes are presented in Table 4.

The second method of determining biotypes uses unsupervised (available without a priori knowledge) statistical data analysis. The data were divided into groups (clusters), so that each of the groups was as homogeneous as possible (the strains within a cluster are related to each other), while 
TABLE 5: Comparison of biotypes of both arbitrary and clusterization (using split into 4 clusters) methods.

\begin{tabular}{|c|c|c|c|c|c|c|c|c|}
\hline \multirow{3}{*}{ Biotype from the arbitrary method } & \multicolumn{8}{|c|}{ Biotype from a dendrogram } \\
\hline & \multicolumn{2}{|c|}{ Red } & \multicolumn{2}{|c|}{ Green } & \multicolumn{2}{|c|}{ Blue } & \multicolumn{2}{|c|}{ Yellow } \\
\hline & $n$ & $\%$ & $n$ & $\%$ & $n$ & $\%$ & $n$ & $\%$ \\
\hline $\mathrm{I}$ & 0 & $0.00 \%$ & 55 & $77.46 \%$ & 0 & $0.00 \%$ & 7 & $14.00 \%$ \\
\hline II & 9 & $75.00 \%$ & 13 & $18.31 \%$ & 0 & $0.00 \%$ & 1 & $2.00 \%$ \\
\hline III & 1 & $8.33 \%$ & 3 & $4.23 \%$ & 10 & $100.00 \%$ & 36 & $72.00 \%$ \\
\hline IV & 2 & $16.67 \%$ & 0 & $0.00 \%$ & 0 & $0.00 \%$ & 6 & $12.00 \%$ \\
\hline
\end{tabular}

TABLE 6: Comparison of the results from the arbitrary and clusterization methods (dendrogram with a division into 3 clusters).

\begin{tabular}{|c|c|c|c|c|c|c|}
\hline \multirow{3}{*}{ Biotype from the arbitrary method } & \multicolumn{6}{|c|}{ Biotype from the dendrogram } \\
\hline & \multicolumn{2}{|c|}{ "Red" } & \multicolumn{2}{|c|}{ "Green" } & \multicolumn{2}{|c|}{ "Blue" } \\
\hline & $n$ & $\%$ & $n$ & $\%$ & $n$ & $\%$ \\
\hline I & 0 & $0.00 \%$ & 55 & $77.46 \%$ & 7 & $11.67 \%$ \\
\hline II & 9 & $75.00 \%$ & 13 & $18.31 \%$ & 1 & $1.67 \%$ \\
\hline III & 1 & $8.33 \%$ & 3 & $4.23 \%$ & 46 & $76.67 \%$ \\
\hline IV & 2 & $16.67 \%$ & 0 & $0.00 \%$ & 6 & $10.00 \%$ \\
\hline
\end{tabular}

clusters were different (strains from different groups have as few common features as possible).

The results of the division into clusters are displayed as dendrograms (diagrams in the shape of a tree showing the relationships and similarities between selected elements). In the case of the most well-fitted dendrogram, strains could be differentiated from the activity of melibiose and tagatose. Thus, 3 biotypes (the main branches of the diagram, Figure 6) were obtained and are marked with the colors red, green, and blue. The figure also indicates the distribution of enzymatic profiles obtained using the arbitrary method: the green cluster, biotype I; red, biotype II; and blue, biotype III.

Additionally, the number of clusters was confirmed using an objective profiling methodology (silhouette method) which gave the dendrogram presented in Figure 7 . The analysis gave 2 clusters marked in the colors red and green. In this method, the number of clusters was selected using the objective method (silhouette). In our observations, the criterion for the rejection of the abovementioned method is that one cluster has 11 observations, while the second has above 100 .

Using the results obtained in the arbitrary method, a third dendrogram was created showing 4 clusters (Figure 8). The distribution of biotypes obtained in the abovementioned method is as follows: the red cluster is mainly biotype II, but also III and IV; the green cluster is mainly biotype I, but also II and III; the blue cluster is only biotype III; and the yellow one is mainly biotype III, but also I, II, and IV.

In addition, a "scree plot" method was used in the identification of the optimal number of clusters (Figure 9). The result of the analysis appears to be consistent with the established arbitrary method, which coincides with the set dendrogram (Figure 8). The graph shows that the elbow is for 4 clusters (because ESS drops sharply up to 4 clusters and then more smoothly). Thus, this method points to 4 clusters, as determined in Figure 8.

After analyzing all three dendrograms, the clustering shown in Figures 6-8 appears reasonable, although the dendrogram in Figure 6 appears to be more consistent from the clinical point of view, because one cluster is formed by strains belonging to one biotype. This is as unlikely as in the case of the dendrogram shown in Figure 8 (one cluster is formed by several strains of different biotypes). A comparison of the biotypes obtained in the two methods is shown in Tables 5 and 6 .

As can be seen in the presented tables, the division into four clusters, despite being supported by an objective method, does not quite make sense from a clinical perspective. In the case of the dendrogram with 4 clusters, there are two clusters where the classified strains constitute less than $7 \%$ and $8 \%$ of strains, respectively. In addition, the distribution of strains in clusters is heterogeneous; that is, one cluster is formed by strains of at least 3 or even 4 biotypes as a result of the arbitrary method. In the case of three clusters, the distribution of strains is relatively homogeneous and grouped within the selected specific biotypes.

\subsection{Advanced Form of Dental Caries in Certain Biotypes}

3.2.1. Arbitrary Method. While analyzing the 4 biotypes obtained using the arbitrary method in terms of the severity of caries, it was noted that the analyzed groups differed significantly ( $p<0.05$; Fisher's exact test) in the occurring biotypes (Table 7, Figure 10).

The analysis shows that biotypes obtained in the arbitrary method do not have a specific use in patients with varying degrees of dental caries severity. The number of strains belonging to biotype IV is too low: 2 strains $(2.06 \%)$ for the noncavitated group and 6 strains (13.04\%) for the cavitated group. Therefore, these criteria were rejected during the assessment of the relationship between the selected biotypes and caries severity (Table 7, Figure 10).

3.2.2. Clusterization Method. While analyzing biotypes in the most well-fitted dendrogram in terms of the severity of caries, 


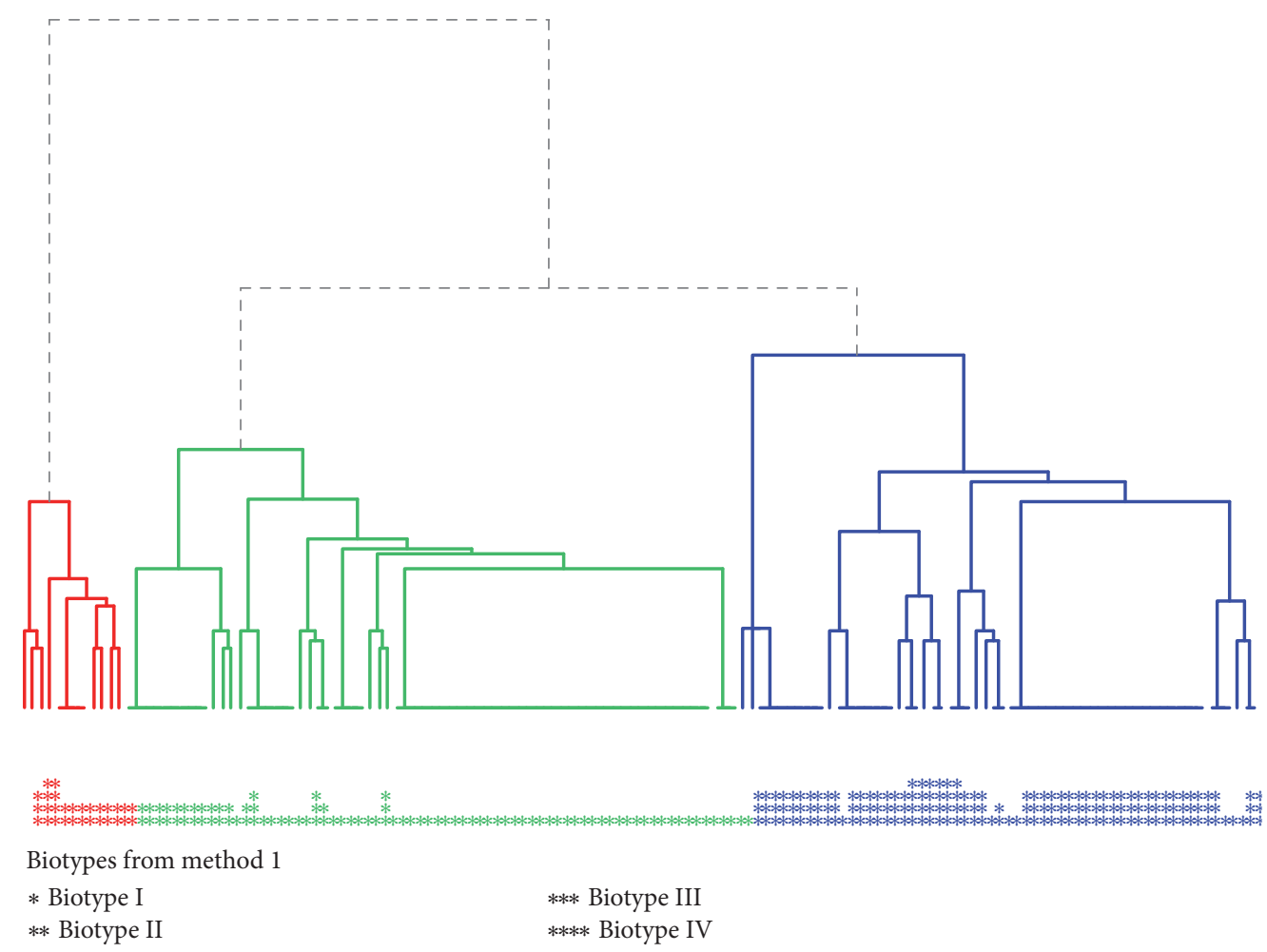

FIGURE 6: Dendrogram with 3 marked S. mutans biotypes in the studied population.

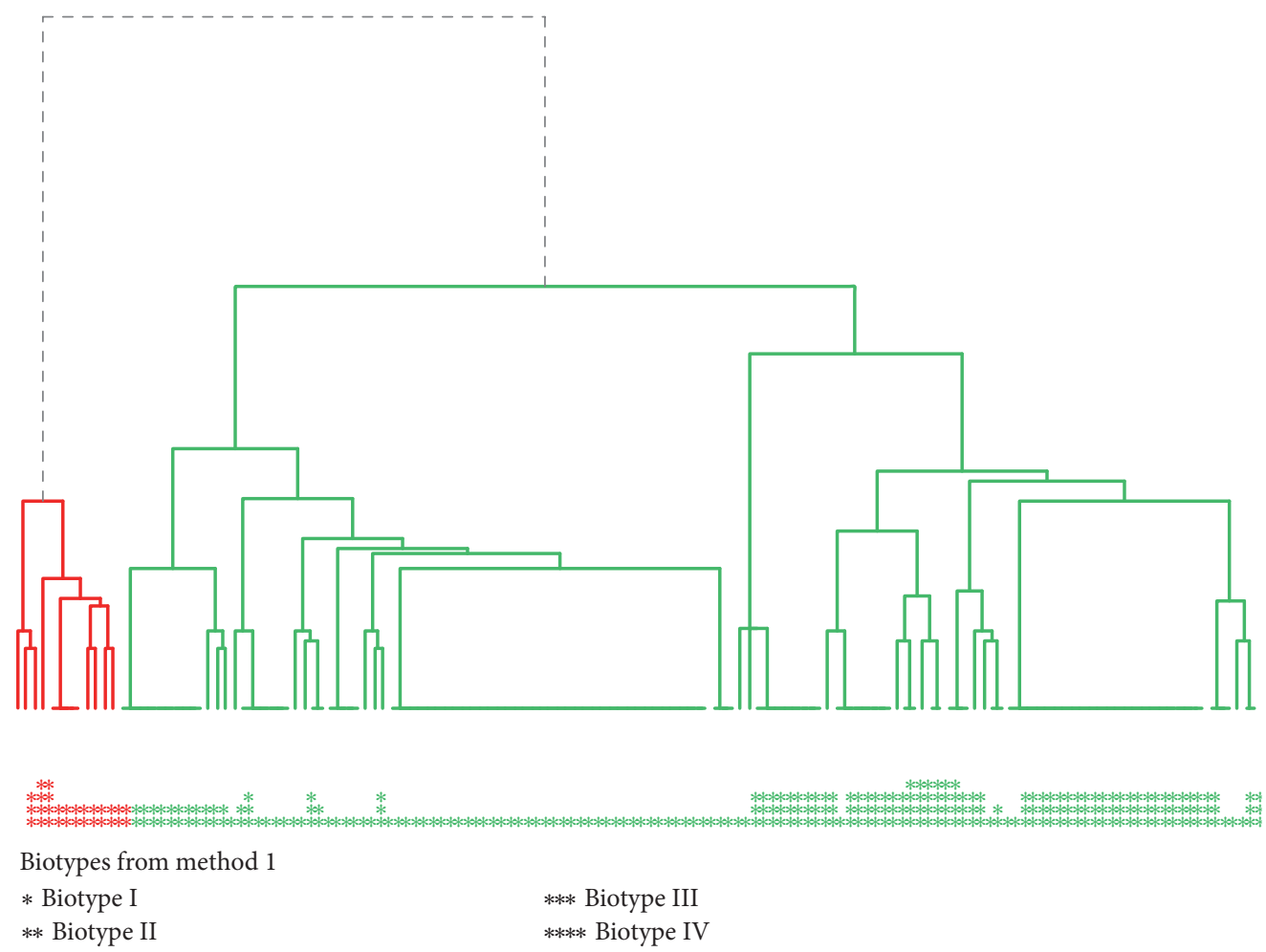

FIGURE 7: Dendrogram with 2 marked S. mutans biotypes in the study population determined by the objective method (silhouette). 


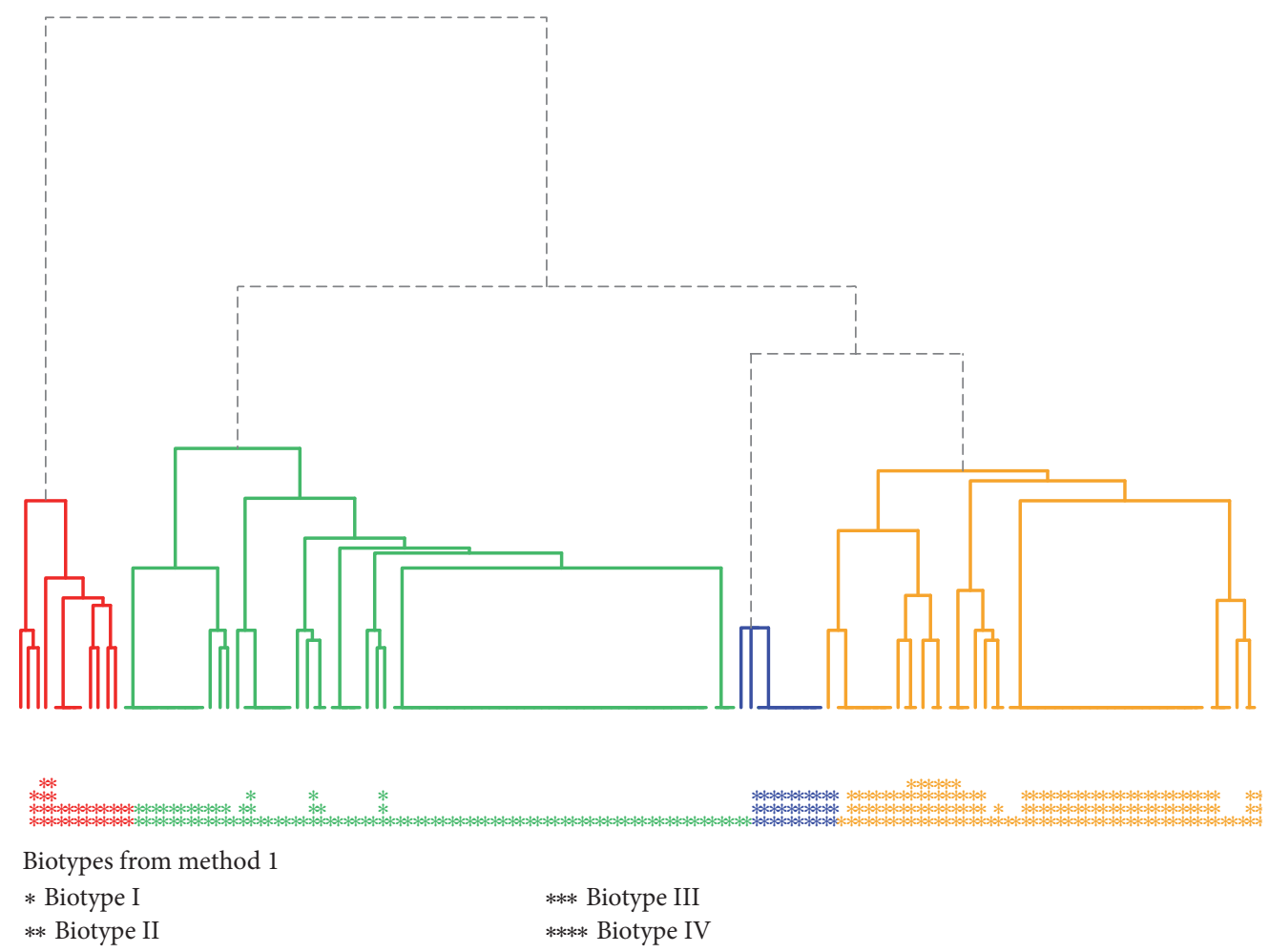

FIGURE 8: Dendrogram with 4 marked S. mutans biotypes in the study population determined by a subjective arbitrary-based method. Colors show the division into 4 obtained biotypes as a dendrogram; stars under it show biotypes of the arbitrary method.

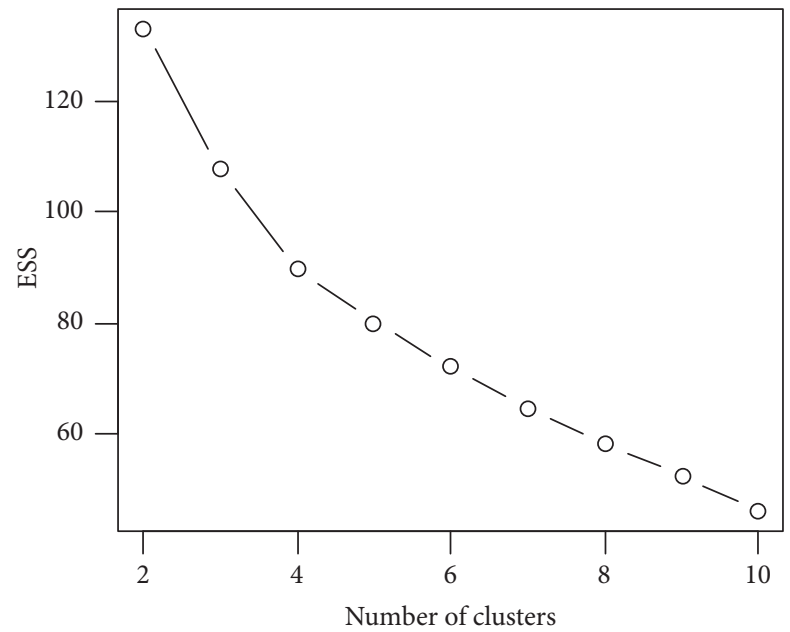

FIGURE 9: Determining the optimal number of clusters using the scree plot method.

it was noted that the analyzed groups differed significantly $(p<0.05$; Fisher's exact test) in the occurring clusters (Table 8, Figure 11).

Although no strain occurred in the noncavitated group in cluster A, the present biotype arrangement seems more reasonable from the clinical point of view. The red cluster is formed by strains from biotype II alone, which lack the activity of inulin, but with active tagatose and partially active

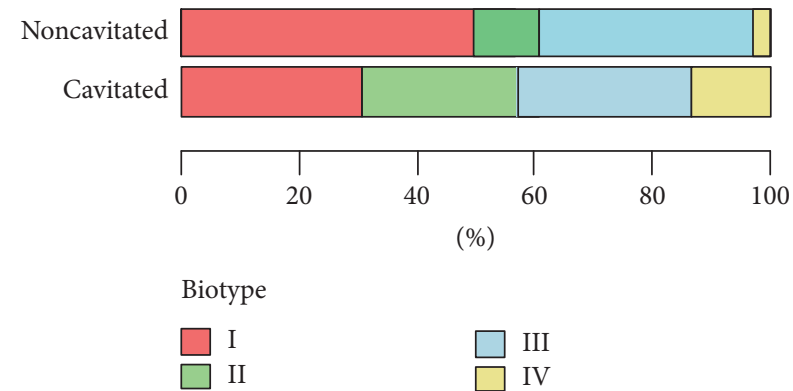

FIGURE 10: The analysis of the obtained biotypes (arbitrary method) in terms of the severity of dental caries. Fisher's exact test; $p<0.05$.

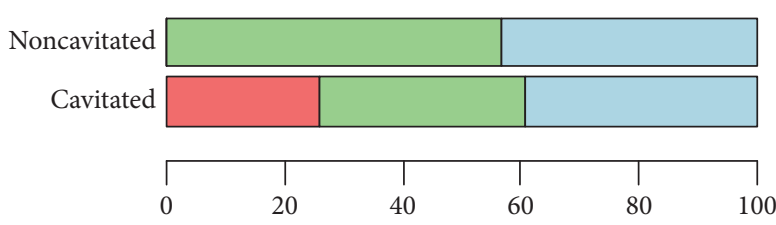

(\%)

Cluster

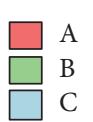

FIGURE 11: Analysis of the obtained clusters (clusterization method) in terms of the severity of dental caries. Fisher's exact test; $p<0.05$. 
TABLE 7: Analysis of the obtained biotypes (arbitrary method) in terms of the severity of dental caries. Fisher's exact test; $p<0.05$. ${ }^{*}$ Fisher's exact test (low expected values in the table).

\begin{tabular}{lccccc}
\hline \multirow{2}{*}{ Biotype } & \multicolumn{2}{c}{ Noncavitated } & \multicolumn{2}{c}{ Cavitated } & \multirow{2}{*}{$p^{*}$} \\
& $n$ & $\%$ & $n$ & $\%$ & \\
\hline I & 48 & $49.48 \%$ & 14 & $30.43 \%$ & \\
II & 11 & $11.34 \%$ & 12 & $26.09 \%$ & $p=0.003$ \\
III & 36 & $37.11 \%$ & 14 & $30.43 \%$ & \\
IV & 2 & $2.06 \%$ & 6 & $13.04 \%$ & \\
\hline
\end{tabular}

TABLE 8: Analysis of the obtained clusters (clusterization method) in terms of the severity of dental caries. Fisher's exact test; $p<0.05$. ${ }^{*}$ Fisher's exact test (low expected values in the table).

\begin{tabular}{lccccc}
\hline \multirow{2}{*}{ Cluster } & \multicolumn{2}{c}{ Noncavitated } & \multicolumn{2}{c}{ Cavitated } & \multirow{2}{*}{$p^{*}$} \\
& $n$ & $\%$ & $n$ & $\%$ & \\
\hline A & 0 & $0.00 \%$ & 12 & $26.09 \%$ & \\
B & 55 & $56.70 \%$ & 16 & $34.78 \%$ & $p<0.001$ \\
C & 42 & $43.30 \%$ & 18 & $39.13 \%$ & \\
\hline
\end{tabular}

melibiose; the green cluster is formed by strains from biotype I lacking the activity of inulin and tagatose, with partially active melibiose; the blue cluster is strains of biotype III, with inulin activity and partially active melibiose and without active tagatose. In addition, the distribution of strains in clusters is comparable (Table 8, Figure 11).

3.3. Sensitivity to Antibiotics in Certain Biotypes. A comparison of mean MIC values for each antibiotic was undertaken, and the range of MIC and $\mathrm{MIC}_{50}$ values is given in Table 9. It has been demonstrated that strains from certain biotypes show different levels of susceptibility to selected antibiotics. As is apparent from the mean MIC, strains belonging to biotype IV were more sensitive to amoxicillin and cefazolin $(p<$ $0.01)$ than to teicoplanin $(p<0.001)$ and erythromycin $(p<$ 0.001 ). Among the strains isolated from children with caries (cavitated group), the strains of biotypes II and IV were the most sensitive to amoxicillin $(p<0.01)$. In the case of strains belonging to biotype IV, strains from the noncavitated group were the most sensitive to amoxicillin $(p<0.01)$. Results obtained in the arbitrary method concur with the results from the clustering into 3 clusters, wherein strains belonging to cluster A (mainly biotypes II and IV) were the most susceptible to amoxicillin $(p<0.001)$ (Table 10). Among the strains isolated from children with caries (cavitated group), strains belonging to cluster A (biotype II, arbitrary method) were the most sensitive to amoxicillin $(p<0.001)$ and erythromycin $(p<0.001)$. In the noncavitated group, strains of cluster C (biotypes III and IV) were the most susceptible to amoxicillin $(p<0.01)$. According to the obtained mean MIC values, amoxicillin was the most effective in biotypes II and IV (similarly in cluster A), and erythromycin was the most effective in biotypes I and II (Table 9). The factor supporting the comparative effectiveness of this method is its reproducibility in the two methods (arbitrary and clusterization method, available without a priori knowledge). Due to the relatively quick and simple procedure, this method may be a valuable prognostic tool in studies of $S$. mutans, especially in terms of the prevention of dental caries in children.

\section{Discussion}

Via evolution, organisms adapt to the environment which they inhabit. Features they developed facilitate their search for food, survival, and proliferation. An extreme example of adaptation to the environmental conditions is obligate parasites, for example, Plasmodium falciparum, which need a definite host to finish their life cycle. The majority of human pathogenic bacteria occur naturally, mostly in the soil, water, or decaying organic matter, and do not require hosts for propagation. The broad adaptability of pathogenic bacteria allows them to be both saprophytes and parasites, depending on the location and conditions under which they currently exist. One should keep in mind that even pathogenic bacteria are opportunists and, as discussed in the Introduction, the occurrence of bacteremia requires many factors. Not only the properties of a bacterial cell but also the conditions in which it exists are important, in this case the host immune condition. Some bacteria, such as facultative anaerobes, seem to prefer a special environment: the human oral cavity [21].

Approximately five quintillion $\left(5 \times 10^{30}\right)$ bacteria have been identified, and it is estimated that there may be about 5 $\times 10^{60}$ in total [22]. Only a few hundred of these species have been described in cases of human infections [23]. Pathogenic bacteria have developed a number of features that enable them to survive and reproduce in a living organism. It can be assumed that some more common pathogens are more adapted to a parasitic lifestyle than others, which may be at the beginning of the "road" to parasitism. Questions arise as to which features distinguish pathogenic species from species unable to infect, which features are essential for a bacterium to parasite in mammals, and what differs commonly isolated pathogens such as $S$. pyogenes from newly emerging pathogens such as $S$. mutans.

Awareness of the characteristics determining the pathogenicity of newly appearing species responsible for bacteremia can contribute to an understanding of the general mechanisms of bacterial infections. Comparison with documented bacterial pathogens will determine which features are most important in the evaluation of bacterial pathogenicity.

The aim of this study was to determine the relationship between the established biotypes among S. mutans strains isolated from children with caries, caries severity, and sensitivity to selected antibiotics.

In our study, we focused our attention on S. mutans strains isolated from dental plaque, a recognized etiological factor of caries. We selected isolates of bacterial strains based on the presence of $S$. mutans in the test material. The frequency of $S$. mutans isolation was approximately $80 \%$ in patients with early childhood caries and $24 \%$ in children without symptoms. The obtained data are consistent with our previous results [24] and also with available literature, where the frequency of $S$. mutans isolation is very diverse and the range of results is from $59 \%$ [25] through $66 \%$ [26] to up to even $100 \%$ [27]. 
TABLE 9: The average values of MIC, MIC range, and $\mathrm{MIC}_{50}(\mathrm{mg} / \mathrm{L})$ for selected antibiotics according to $S$. mutans biotypes set out in the arbitrary method.

\begin{tabular}{|c|c|c|c|c|}
\hline \multirow{2}{*}{ 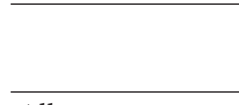 } & \multicolumn{4}{|c|}{ Biotypes from the arbitrary method } \\
\hline & I & II & III & IV \\
\hline \multicolumn{5}{|l|}{ All strains } \\
\hline \multicolumn{5}{|l|}{ Amoxicillin } \\
\hline MIC, range & $0.007-0.5$ & $0.007-0.5$ & $0.007-0.5$ & $0.007-0.25$ \\
\hline $\mathrm{MIC}_{50}$ & 0.05 & 0.05 & 0.05 & 0.05 \\
\hline MIC, mean & 0.092 & 0.059 & 0.084 & 0.042 \\
\hline \multicolumn{5}{|l|}{ Cefazolin } \\
\hline MIC, range & $0.02-1.5$ & $0.02-1.5$ & $0.02-1.5$ & $0.03-1.5$ \\
\hline $\mathrm{MIC}_{50}$ & 0.07 & 0.07 & 0.07 & 0.07 \\
\hline MIC, mean & 0.153 & 0.152 & 0.158 & 0.169 \\
\hline \multicolumn{5}{|l|}{ Teicoplanin } \\
\hline MIC, range & $0.1-1.5$ & $0.1-1.5$ & $0.1-1.5$ & $0.1-1$ \\
\hline $\mathrm{MIC}_{50}$ & 0.5 & 0.5 & 0.5 & 0.5 \\
\hline MIC, mean & 0.73 & 0.717 & 0.698 & 0.606 \\
\hline \multicolumn{5}{|l|}{ Erythromycin } \\
\hline MIC, range & $0.015-1$ & $0.015-1$ & $0.015-1$ & $0.04-1$ \\
\hline $\mathrm{MIC}_{50}$ & 0.07 & 0.07 & 0.07 & 0.07 \\
\hline MIC, mean & 0.097 & 0.081 & 0.136 & 0.188 \\
\hline \multicolumn{5}{|c|}{ Noncavitated group } \\
\hline \multicolumn{5}{|c|}{ Amoxicillin } \\
\hline MIC, range & $0.007-0.5$ & $0.015-0.5$ & $0.007-0.5$ & $0.015-0.05$ \\
\hline $\mathrm{MIC}_{50}$ & 0.05 & 0.05 & 0.05 & 0.05 \\
\hline MIC, mean & 0.096 & 0.08 & 0.078 & 0.012 \\
\hline \multicolumn{5}{|l|}{ Cefazolin } \\
\hline MIC, range & $0.02-1.5$ & $0.02-0.2$ & $0.02-1.5$ & $0.03-0.1$ \\
\hline $\mathrm{MIC}_{50}$ & 0.07 & 0.07 & 0.07 & 0.07 \\
\hline MIC, mean & 0.153 & 0.15 & 0.153 & 0.15 \\
\hline \multicolumn{5}{|l|}{ Teicoplanin } \\
\hline MIC, range & $0.1-1.5$ & $0.1-1.5$ & $0.1-1.5$ & $0.1-1$ \\
\hline $\mathrm{MIC}_{50}$ & 0.5 & 0.5 & 0.5 & 0.5 \\
\hline MIC, mean & 0.734 & 0.744 & 0.726 & 0.7 \\
\hline \multicolumn{5}{|l|}{ Erythromycin } \\
\hline MIC, range & $0.015-1$ & $0.015-0.5$ & $0.015-1$ & $0.04-0.07$ \\
\hline $\mathrm{MIC}_{50}$ & 0.07 & 0.07 & 0.07 & 0.07 \\
\hline MIC, mean & 0.097 & 0.061 & 0.091 & 0.05 \\
\hline \multicolumn{5}{|l|}{ Cavitated group } \\
\hline \multicolumn{5}{|l|}{ Amoxicillin } \\
\hline MIC, range & $0.015-0.5$ & $0.007-0.5$ & $0.007-0.5$ & $0.007-0.25$ \\
\hline $\mathrm{MIC}_{50}$ & 0.05 & 0.05 & 0.04 & 0.04 \\
\hline MIC, mean & 0.077 & 0.039 & 0.099 & 0.052 \\
\hline \multicolumn{5}{|l|}{ Cefazolin } \\
\hline MIC, range & $0.02-1.5$ & $0.02-1.5$ & $0.02-1.5$ & $0.03-1.5$ \\
\hline $\mathrm{MIC}_{50}$ & 0.07 & 0.07 & 0.08 & 0.08 \\
\hline MIC, mean & 0.154 & 0.154 & 0.171 & 0.175 \\
\hline \multicolumn{5}{|l|}{ Teicoplanin } \\
\hline MIC, range & $0.1-1.5$ & $0.1-1.5$ & $0.1-1.5$ & $0.1-1$ \\
\hline $\mathrm{MIC}_{50}$ & 0.5 & 0.5 & 0.5 & 0.35 \\
\hline MIC, mean & 0.716 & 0.692 & 0.627 & 0.575 \\
\hline
\end{tabular}


TABLE 9: Continued.

\begin{tabular}{lcccc}
\hline & \multicolumn{2}{c}{ Biotypes from the arbitrary method } \\
& I & II & III & IV \\
\hline Erythromycin & & & $0.015-1$ & $0.04-1$ \\
MIC, range & $0.015-1$ & $0.015-1$ & 0.07 & 0.07 \\
MIC & 0.07 & 0.07 & 0.252 & 0.233 \\
MIC, mean & 0.098 & 0.099 & \\
\hline
\end{tabular}

Biotyping allows the combination of strains with similar characteristics into groups called biotypes. There are different approaches to strain typing. In the present study, we applied biotyping of $S$. mutans strains upon the profiles of enzymatic activity in a commercial assay: STREPTOtest 24.

In the case of oral streptococcosis, biotype I or the green cluster (B) dominates (S. mutans strains with inactive inulin and tagatose and with partial activity of melibiose). Other biotypes were observed less frequently or not at all. Interestingly, in the case of systematic infections, the dominance of biotype I is not so much in favor of other more often isolated biotypes [28]. However, it is difficult to discuss the biotypes specific to different types of infections, given the limited number of undertaken research studies.

There are no specific (conventionally adopted) biotypes and thus enzymes to classify (perform biotyping) for the $S$. mutans species. In this paper, we attempted to determine biotypes for dental caries. Two approaches to the determining of enzymes useful to biotyping were adopted. One of these was the arbitrary method of enzymes selection, where the incidence of the enzyme activity in the studied population was adopted as a criterion. On this basis, we noticed that, to differentiate strains, inulin (INU), melibiose (MLB), and tagatose (TGT) have the best activity. These results are only partly consistent with the results of Yoo et al. [14], where, similar to our study, strains with inactive inulin (INU) formed the most dominant biotype I. In contrast to our strains of biotype I which showed no tagatose activity, strains of biotype I determined by Yoo showed variable activity of tagatose and the presence of an enzyme that degraded melibiose (MLB), while our strains showed variable levels of activity for this enzyme.

The method seems to be promising, especially in the context of the current understanding of the mechanisms of vertical and horizontal bacterial transmission. Future studies should examine whether our proposed biotypes are characteristic for family members (mother, child, and sibling). This would allow the development of caries prevention programs based on screening tests in a population of healthy people or people from risk groups.

Our results on $S$. mutans susceptibility to the selected antibiotics are opposite to the results of Longman et al. [29] and Bryskier [30], whose amoxicillin-resistant strains showed sensitivity to erythromycin. In our case, the strains of biotypes III and IV, which were less sensitive to erythromycin, were found to be sensitive to amoxicillin. These results are consistent between the two used biotyping methods (arbitrary division into biotypes and the method of clusterization into three clusters). In the case of dental patients in the
United Kingdom who received amoxicillin as prophylaxis, most isolates were resistant to erythromycin. The reason for the occurrence of erythromycin-resistant strains, especially in patients taking amoxicillin prophylaxis, is not known. Our results are similar to the results of Harrison et al. [31], who found no strains resistant to erythromycin among oral streptococci from healthy volunteers. However, it is difficult to compare the results obtained in this study with previous reports due to differences in methodology, target group, and criteria for determining the resistance to selected antibiotics. In the oral streptococci, resistance to amoxicillin and erythromycin has been studied with variable feature [32]. It can be assumed that the variable sensitivity to antibiotics of oral streptococci is dependent on the changing maturity of the mouth microbiome. This happens in the case of Streptococcus salivarius appearing during adolescence of oral flora in the individual life. This highlights the potential role of this species in the shaping of sensitivity of the mouth and throat to antibiotics [33, 34].

In the case of viridans group streptococci (VGS) which most often occur in the oral cavity, opportunistic species (emerging pathogens) may also occur, and these are responsible for such rare diseases as infectious endocarditis (IE), bacteremia, or ischemic stroke $[35,36]$. In these cases, it appears to be decisive to determine the antimicrobial susceptibility of VGS which belong to the oral microflora and may be a potential risk factor for the development of the abovementioned diseases in dental patients.

In our identification of the bacteria isolated from the oral cavity belonging to the VGS using an API Strep test (bioMérieux, France), we determined the susceptibility of strains (MIC) to penicillin, ampicillin, and vancomycin. The most frequently isolated species of oral cavity microbiota include, for example, S. mutans, and $13 \%$ of these species are resistant to penicillin, while all are sensitive to vancomycin. It follows that antimicrobial resistance of VGS should be measured routinely and regularly in the local community. Based on the results of bacterial susceptibility to certain antibiotics and the forming of drug resistance among the strains of the specific biotypes, it should be possible to take preventive and therapeutic decisions in risk groups, including pediatric patients predisposed to the development of diseases including caries. In addition, one should consider empirical treatment of patients from the so-called "infective window" and groups at risk of acute VGS infections [37].

In our study, a varying degree of sensitivity by $S$. mutans strains can be observed in the selected biotypes depending on the severity of dental caries. Strains grouped in clusters A and B from children with advanced caries (cavitated group) 
TABLE 10: The average values of MIC, MIC range, and $\mathrm{MIC}_{50}(\mathrm{mg} / \mathrm{L})$ for selected antibiotics according to $S$. mutans clusters/biotypes set out in the clusterization method.

Clusters from the clusterization method

A B C

\begin{tabular}{|c|c|c|c|}
\hline \multicolumn{4}{|l|}{ All strains } \\
\hline \multicolumn{4}{|l|}{ Amoxicillin } \\
\hline MIC, range & $0.015-0.05$ & $0.007-0.5$ & $0.007-0.5$ \\
\hline $\mathrm{MIC}_{50}$ & 0.05 & 0.05 & 0.05 \\
\hline MIC, mean & 0.012 & 0.085 & 0.09 \\
\hline \multicolumn{4}{|l|}{ Cefazolin } \\
\hline MIC, range & $0.03-0.1$ & $0.02-1.5$ & $0.02-1.5$ \\
\hline $\mathrm{MIC}_{50}$ & 0.07 & 0.07 & 0.07 \\
\hline MIC, mean & 0.15 & 0.153 & 0.16 \\
\hline \multicolumn{4}{|l|}{ Teicoplanin } \\
\hline MIC, range & $0.1-1$ & $0.1-.5$ & $0.1-1.5$ \\
\hline $\mathrm{MIC}_{50}$ & 0.5 & 0.5 & 0.5 \\
\hline MIC, mean & 0.7 & 0.729 & 0.69 \\
\hline \multicolumn{4}{|l|}{ Erythromycin } \\
\hline MIC, range & $0.04-0.07$ & $0.015-1$ & $0.015-1$ \\
\hline $\mathrm{MIC}_{50}$ & 0.07 & 0.07 & 0.07 \\
\hline MIC, mean & 0.05 & 0.092 & 0.151 \\
\hline \multicolumn{4}{|c|}{ Noncavitated group } \\
\hline \multicolumn{4}{|c|}{ Amoxicillin } \\
\hline MIC, range & & $0.007-0.5$ & $0.007-0.5$ \\
\hline $\mathrm{MIC}_{50}$ & & 0.05 & 0.05 \\
\hline MIC, mean & & 0.089 & 0.083 \\
\hline \multicolumn{4}{|l|}{ Cefazolin } \\
\hline MIC, range & & $0.02-1.5$ & $0.02-1.5$ \\
\hline $\mathrm{MIC}_{50}$ & & 0.07 & 0.07 \\
\hline MIC, mean & & 0.152 & 0.154 \\
\hline Teicoplanin & N/A & & \\
\hline MIC, range & & $0.1-1.5$ & $0.1-1.5$ \\
\hline $\mathrm{MIC}_{50}$ & & 0.5 & 0.5 \\
\hline MIC, mean & & 0.737 & 0.724 \\
\hline \multicolumn{4}{|l|}{ Erythromycin } \\
\hline MIC, range & & $0.015-1$ & $0.015-1$ \\
\hline $\mathrm{MIC}_{50}$ & & 0.07 & 0.07 \\
\hline MIC, mean & & 0.082 & 0.1 \\
\hline \multicolumn{4}{|l|}{ Cavitated group } \\
\hline \multicolumn{4}{|l|}{ Amoxicillin } \\
\hline MIC, range & $0.015-0.05$ & $0.007-0.5$ & $0.007-0.5$ \\
\hline $\mathrm{MIC}_{50}$ & 0.05 & 0.05 & 0.04 \\
\hline MIC, mean & 0.012 & 0.074 & 0.107 \\
\hline \multicolumn{4}{|l|}{ Cefazolin } \\
\hline MIC, range & $0.03-0.1$ & $0.02-1.5$ & $0.02-1.5$ \\
\hline $\mathrm{MIC}_{50}$ & 0.07 & 0.07 & 0.08 \\
\hline MIC, mean & 0.15 & 0.156 & 0.175 \\
\hline \multicolumn{4}{|l|}{ Teicoplanin } \\
\hline MIC, range & $0.1-1$ & $0.1-1.5$ & $0.1-1.5$ \\
\hline $\mathrm{MIC}_{50}$ & 0.5 & 0.5 & 0.35 \\
\hline MIC, mean & 0.7 & 0.699 & 0.611 \\
\hline
\end{tabular}


TABle 10: Continued.

\begin{tabular}{cccc}
\hline & \multicolumn{2}{c}{ Clusters from the clusterization method } \\
& $\mathrm{A}$ & $\mathrm{B}$ & $\mathrm{C}$ \\
\hline Erythromycin & & & $0.015-1$ \\
MIC, range & $0.04-0.07$ & 0.07 & 0.07 \\
MIC $_{50}$ & 0.07 & 0.126 & 0.271 \\
MIC, mean & 0.05 & \\
\hline
\end{tabular}

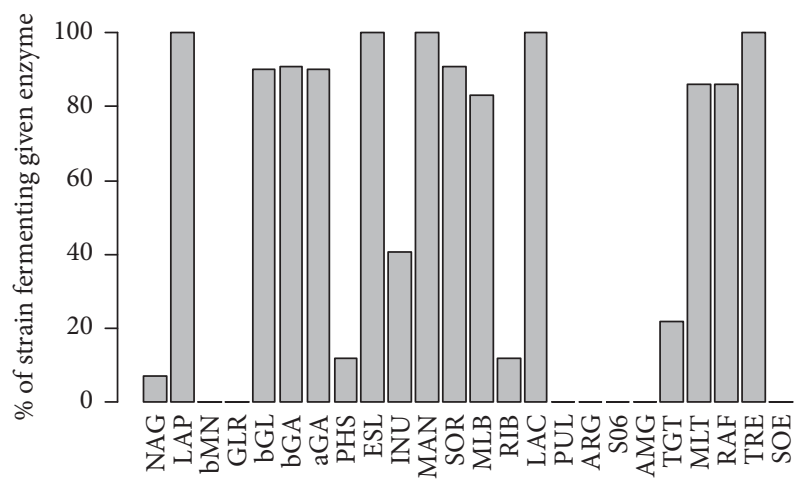

FIGURE 12: Enzymatic activity in STREPTOtest 24 of bacteria from S. mutans species.

showed sensitivity to amoxicillin and erythromycin $(p<$ 0.001). Strains grouped within clusters $B$ and $C$ from the noncavitated group showed similar sensitivity to amoxicillin and erythromycin. Interestingly, the results of the analysis of sensitivity to the abovementioned antibiotics in these clusters are characterized by the determined phenotype of the tested strains; that is, strains grouped in clusters B and C at the same time were characterized by inactive tagatose and showed varying activity of melibiose. Strains forming cluster A (mainly biotype II) were characterized by a peak sensitivity to amoxicillin and erythromycin. This group includes strains of a different phenotype compared to the above-described clusters B and C, with tagatose activity but with no inulin activity and a variable melibiose activity. In all cases, a heterogeneous distribution of strains degrading/not degrading melibiose can be observed. Melibiose decay is widely discussed with regard to differentiating S. mutans strains [14]. Facklam described biotypes for clinical isolates of $S$. mutans from both dental plaque and blood. In that research, the frequency of the particular enzymes was comparable to those achieved in our study (above 90\%, mannose, trehalose, sorbitol, and esculin) (Figure 12). In the case of melibiose, $83.22 \%$ of our strains demonstrated the activity of that enzyme, while Facklam observed this feature in less than half of the strains isolated from plaque ( $43 \%$ ) and $88 \%$ of the strains isolated from blood [28].

Colby et al. found that strains of $S$. mutans not fermenting melibiose constitute a genetically heterogeneous group. According to these authors, the lack of distribution of this saccharide may be a result of different genetic changes, most often caused by a chromosomal deletion covering the multiple sugar metabolism operon (msm) [38]. In our case, there are too few strains fermenting melibiose to permit discussion of grouping dependent only on this feature. In addition, the heterogeneity of MLB distribution in established biotypes/clusters prevents the drawing of conclusions for the study population.

Primary care physicians should make conscious use of antibiotic therapy, especially in infections of the upper respiratory tract. Awareness of the increasing resistance of VGS bacteria to commonly used antibiotics $[39,40]$ should enhance preventive measures using knowledge about the available diagnostic methods allowing the determination of the prevalence of local resistance which may influence further decisions on the use of empirical therapy and prophylaxis in certain populations and also in hospital wards where the number of multidrug-resistant strains is increasing [41].

\section{Ethical Approval}

The study procedure was approved by the Bioethical Committee of the Jagiellonian University in Kraków (Opinion no. KBET/281/B/2014).

\section{Consent}

Informed written consent was obtained from all patients prior to enrolment.

\section{Conflicts of Interest}

All authors confirm that there are no conflicts of interest.

\section{Acknowledgments}

The authors would like to thank Doctor Elżbieta Karczewska, Professor at the Department of Pharmaceutical Microbiology, Jagiellonian University Medical College, Kraków, Poland, for her professional guidance in microbiology. They would also like to thank Mr. Łukasz Derylo for his professional and statistical guidance. This study was supported by the National Research and Development Center (MNISW/2016/DIR/181/NN) within the framework of the project "Best of the Best!" Operational Program Knowledge Education Development 2014-2020. Research was conducted at the Jagiellonian University Medical College. The Jagiellonian University Medical College is a beneficiary of a "Best of the Best!" grant from the Operational Program Knowledge Education Development 2014-2020 (Measure 3.3 of the Higher Education Internationalization Program). The study was also supported by Jagiellonian University Programs nos. K/ZDS/005485, K/ZDS/005484, and K/DSC/003537. 


\section{References}

[1] K. Nakano, H. Inaba, R. Nomura et al., "Detection of cariogenic Streptococcus mutans in extirpated heart valve and atheromatous plaque specimens," Journal of Clinical Microbiology, vol. 44, no. 9, pp. 3313-3317, 2006.

[2] C.-J. Jung, C.-Y. Yeh, C.-T. Shun et al., "Platelets enhance biofilm formation and resistance of endocarditis-inducing streptococci on the injured heart valve," Journal of Infectious Diseases, vol. 205, no. 7, pp. 1066-1075, 2012.

[3] R. Nomura, M. Otsugu, S. Naka et al., "Contribution of the interaction of Streptococcus mutans serotype k strains with fibrinogen to the pathogenicity of infective endocarditis," Infection and Immunity, vol. 82, no. 12, pp. 5223-5234, 2014.

[4] D. McGhie, J. G. Hutchison, F. Nye, and A. P. Ball, "Infective endocarditis caused by Streptococcus mutans," British Heart Journal, vol. 39, no. 4, pp. 456-458, 1977.

[5] R. Nomura, M. Hamada, K. Nakano, H. Nemoto, K. Fujimoto, and T. Ooshima, "Repeated bacteraemia caused by Streptococcus mutans in a patient with Sjögren's syndrome," Journal of Medical Microbiology, vol. 56, no. 7, pp. 988-992, 2007.

[6] T. Fujiwara, K. Nakano, M. Kawaguchi et al., "Biochemical and genetic characterization of serologically untypable Streptococcus mutans strains isolated from patients with bacteremia," European Journal of Oral Sciences, vol. 109, no. 5, pp. 330-334, 2001.

[7] S. Tonomura, M. Ihara, T. Kawano et al., "Intracerebral hemorrhage and deep microbleeds associated with cnm-positive Streptococcus mutans; A hospital cohort study," Scientific Reports, vol. 6, Article ID 20074, 2016.

[8] K. Nakano, R. Nomura, M. Matsumoto, and T. Ooshima, "Roles of oral bacteria in cardiovascular diseases - From molecular mechanisms to clinical cases: Cell-surface structures of novel serotype $\mathrm{k}$ streptococcus mutans strains and their correlation to virulence," Journal of Pharmacological Sciences, vol. 113, no. 2, pp. 120-125, 2010.

[9] O. Ioannidis, E. Kakoutis, H. Katsifa et al., "Streptococcus mutans: A rare cause of retroperitoneal abscess," Advances in Medical Sciences, vol. 56, no. 1, pp. 113-118, 2011.

[10] R. Facklam, "What happened to the streptococci: overview of taxonomic and nomenclature changes," Clinical Microbiology Reviews, vol. 15, no. 4, pp. 613-630, 2002.

[11] L. Postek-Stefańska, T. Mazur, I. Wysoczańska-Jankowicz, L. Borkowski et al., "Porównanie skuteczności eliminacji bakterii z kanałów korzeniowych po chemomechanicznym opracowaniu metodą ręczną i maszynową," Dental and Medical Problems, vol. 48, no. 4, pp. 496-504, 2011.

[12] B. Leda, T. Niedźwiecki, T. Łukaszewski, and B. DorockaBobkowska, "Carriage of Streptococcus Species and Selected Saliva Properties in Complete Denture Wearers," Dental and Medical Problems, vol. 45, no. 1, pp. 37-41, 2008.

[13] M. Dabrowska-Szponar and H. Kubielas, "Serologiczna i genetyczna analiza paciorkowców grupy B izolowanych od dorosłych pacjentów," Medycyna Doświadczalna i Mikrobiologia, vol. 58, pp. 283-289, 2006.

[14] S. Y. Yoo, S. J. Park, D. K. Jeong, K. W. Kim, S. H. Lim, and S. H. Lee, "Isolation and characterization of the mutans streptococci from the dental plaques in Koreans," Journal of Microbiology, vol. 45, no. 3, pp. 246-255, 2007.

[15] WHO, Oral Health Surveys. Basic Methods, World Health Organization, Geneva, 4th edition, 1997.
[16] "International Caries Detection and Assessment System Coordinating Committee Rationale and Evidence for the International Caries Detection and Assessment System (ICDAS II) 2012".

[17] S. H. Wei and N. P. Lang, "Periodontal epidemiological indices for children and adolescents: II. Evaluation of oral hygiene; III. Clinical applications.", Pediatric dentistry, vol. 4, no. 1, pp. 6473, 1982.

[18] G. H. Hildebrandt and W. A. Bretz, "Comparison of culture media and chairside assays for enumerating mutans streptococci," Journal of Applied Microbiology, vol. 100, no. 6, pp. 13391347, 2006.

[19] A. K. Wan, W. K. Seow, L. J. Walsh, and P. S. Bird, "Comparison of five selective media for the growth and enumeration of Streptococcus mutans," Australian Dental Journal, vol. 47, no. 1, pp. 21-26, 2002.

[20] F. Shafiee, A. A. Moghadamnia, Z. Shahandeh, F. Sadighian, and E. Khodadadi, "Evaluation of the antibacterial effects of aqueous and ethanolic leaf extracts of Aloysia Citriodora (Lemon verbena) on Streptococcus mutans and Streptococcus sobrinus," Electronic physician, vol. 8, no. 12, pp. 3363-3368, 2016.

[21] P. E. Kolenbrander, R. N. Andersen, D. S. Blehert, P. G. Egland, J. S. Foster, and R. J. Palmer Jr., "Communication among oral bacteria," Microbiology and Molecular Biology Reviews, vol. 66, no. 3, pp. 486-505, 2002.

[22] W. B. Whitman, D. C. Coleman, and W. J. Wiebe, "Prokaryotes: the unseen majority," Proceedings of the National Academy of Sciences of the United States of America, vol. 95, no. 12, pp. 65786583, 1998.

[23] R. A. Harvey, P. C. Champe, and B. D. Fisher, "Lippincotts Illustrated Reviews," in Lippincott, pp. 332-340, Williams \& Wilkins, Philadelphia, USA, 2007.

[24] W. Krzyściak, K. K. Pluskwa, J. Piątkowski et al., “The usefulness of biotyping in the determination of selected pathogenicity determinants in Streptococcus mutans," BMC Microbiology, vol. 14, no. 1, article no. 194, 2014.

[25] C. A. Palmer, R. Kent Jr., C. Y. Loo et al., "Diet and caries-associated bacteria in severe early childhood caries," Journal of Dental Research, vol. 89, no. 11, pp. 1224-1229, 2010.

[26] S. Fragkou, C. Balasouli, O. Tsuzukibashi et al., "Streptococcus mutans, Streptococcus sobrinus and Candida albicans in oral samples from caries-free and caries-active children," European Archives of Paediatric Dentistry, vol. 17, no. 5, pp. 367-375, 2016.

[27] E.-J. Choi, S.-H. Lee, and Y.-J. Kim, "Quantitative real-time polymerase chain reaction for Streptococcus mutans and Streptococcus sobrinus in dental plaque samples and its association with early childhood caries," International Journal of Paediatric Dentistry, vol. 19, no. 2, pp. 141-147, 2009.

[28] R. R. Facklam, "Characteristics of Streptococcus mutans isolated from human dental plaque and blood," International Journal of Systematic Bacteriology, vol. 24, no. 3, pp. 313-319, 1974.

[29] L. P. Longman, P. K. Pearce, P. McGowan, P. Hardy, and M. V. Martin, "Antibiotic-resistant oral streptococci in dental patients susceptible to infective endocarditis," Journal of Medical Microbiology, vol. 34, no. 1, pp. 33-37, 1991.

[30] A. Bryskier, "Viridans group streptococci: A reservoir of resistant bacteria in oral cavities," Clinical Microbiology and Infection, vol. 8, no. 2, pp. 65-69, 2002.

[31] G. A. J. Harrison, W. P. Stross, M. P. Rubin, R. M. Davies, and D. C. E. Speller, "Resistance in oral streptococci after repeated 
three-dose erythromycin prophylaxis," Journal of Antimicrobial Chemotherapy, vol. 15, no. 4, pp. 471-479, 1985.

[32] P. J. Southall, N. J. Mahy, R. M. Davies, and D. C. E. Speller, "Resistance in oral streptococci after repeated two-dose amoxycillin prophylaxis," Journal of Antimicrobial Chemotherapy, vol. 12, no. 2, pp. 141-146, 1983.

[33] T. H. Palma, E. N. Harth-Chú, J. Scott, R. N. Stipp et al., "Oral cavities of healthy infants harbour high proportions of Streptococcus salivarius strains with phenotypic and genotypic resistance to multiple classes of antibiotics," Journal of Medical Microbiology, vol. 65, no. 12, pp. 1456-1464, 2016.

[34] T. Nakajima, S. Nakanishi, C. Mason et al., "Population structure and characterization of viridans group streptococci (VGS) isolated from the upper respiratory tract of patients in the community," Ulster Medical Journal, vol. 82, no. 3, pp. 164-168, 2013.

[35] S. Süzük, B. Kaşkatepe, and M. Çetin, "Antimicrobial susceptibility against penicillin, ampicillin and vancomycin of viridans group Streptococcus in oral microbiota of patients at risk of infective endocarditis," Le Infezioni in Medicina, vol. 24, no. 3, pp. 190-193, 2016.

[36] B. Nilson, L. Olaison, and M. Rasmussen, "Clinical presentation of infective endocarditis caused by different groups of non-beta haemolytic streptococci," European Journal of Clinical Microbiology and Infectious Diseases, vol. 35, no. 2, pp. 215-218, 2016.

[37] S. A. Shelburne, R. E. Lasky, P. Sahasrabhojane, J. T. Tarrand, and K. V. I. Rolston, "Development and validation of a clinical model to predict the presence of $\beta$-lactam resistance in viridans group streptococci causing bacteremia in neutropenic cancer patients," Clinical Infectious Diseases, vol. 59, no. 2, pp. 223-230, 2014.

[38] S. M. Colby, D. J. Harrington, and R. R. Russell, "Identification and genetic characterisation of melibiose-negative isolates of Streptococcus mutans," Caries Research, vol. 29, no. 5, pp. 407412, 1995.

[39] C. E. Goldsmith, Y. Hara, T. Sato et al., "Comparison of antibiotic susceptibility in viridans group streptococci in low and high antibiotic-prescribing General Practices," Journal of Clinical Pharmacy and Therapeutics, vol. 40, no. 2, pp. 204-207, 2015.

[40] D. Rozkiewicz, T. Daniluk, M. Sciepuk et al., "Prevalence rate and antibiotic susceptibility of oral viridans group streptococci (VGS) in healthy children population.," Advances in medical sciences, vol. 51, pp. 191-195, 2006.

[41] M. Pietsch, C. Eller, C. Wendt et al., "Molecular characterisation of extended-spectrum $\beta$-lactamase (ESBL)-producing Escherichia coli isolates from hospital and ambulatory patients in Germany," Veterinary Microbiology, 2015. 


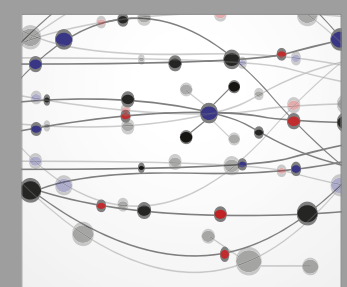

The Scientific World Journal
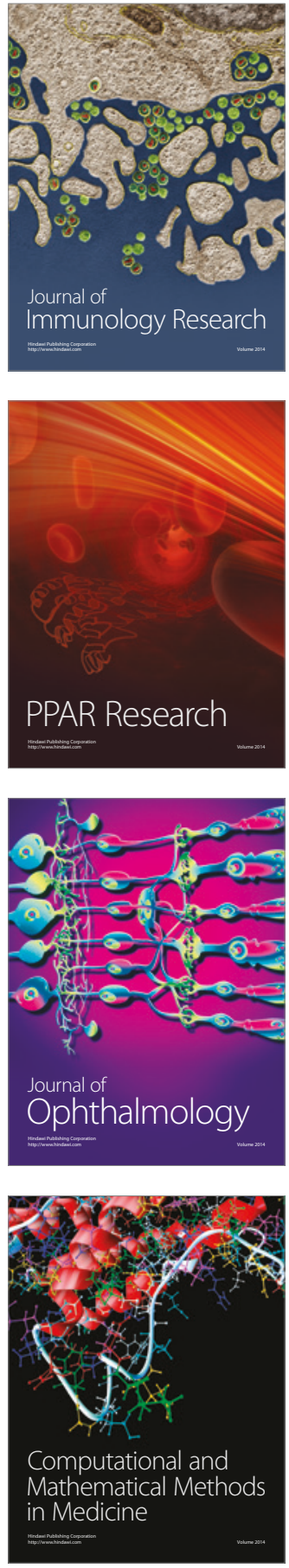

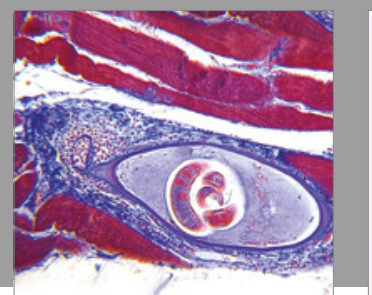

Gastroenterology Research and Practice
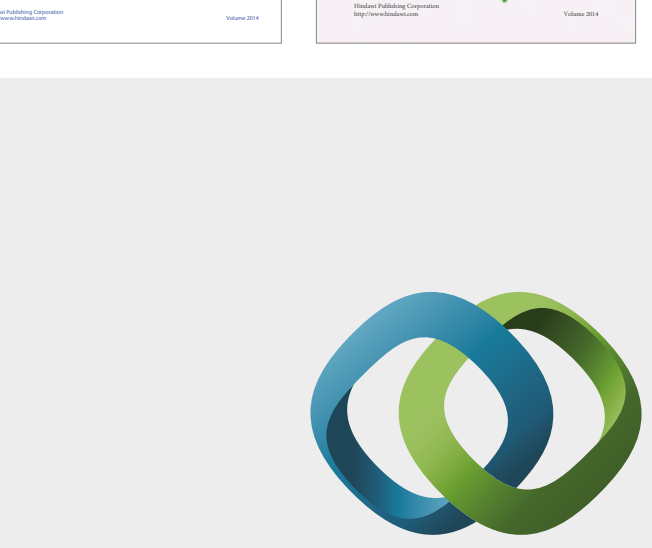

\section{Hindawi}

Submit your manuscripts at

https://www.hindawi.com
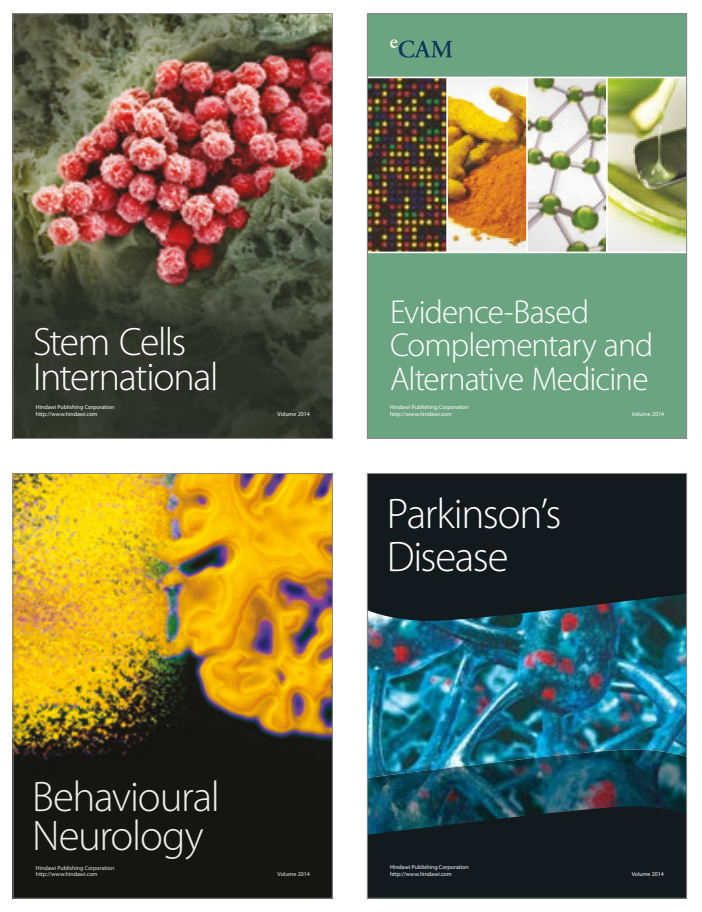
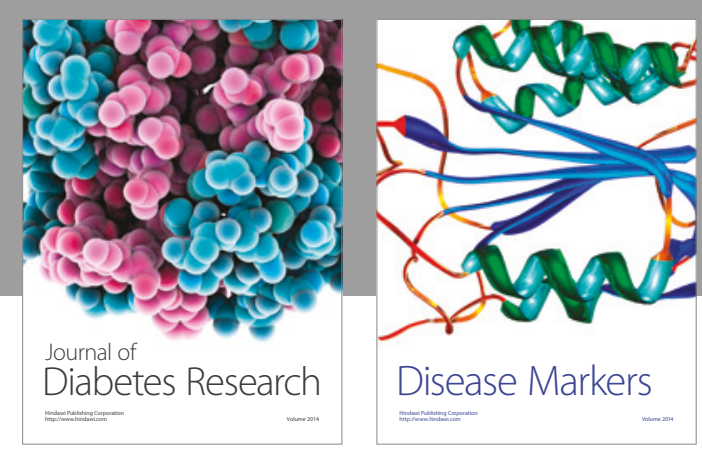

Disease Markers
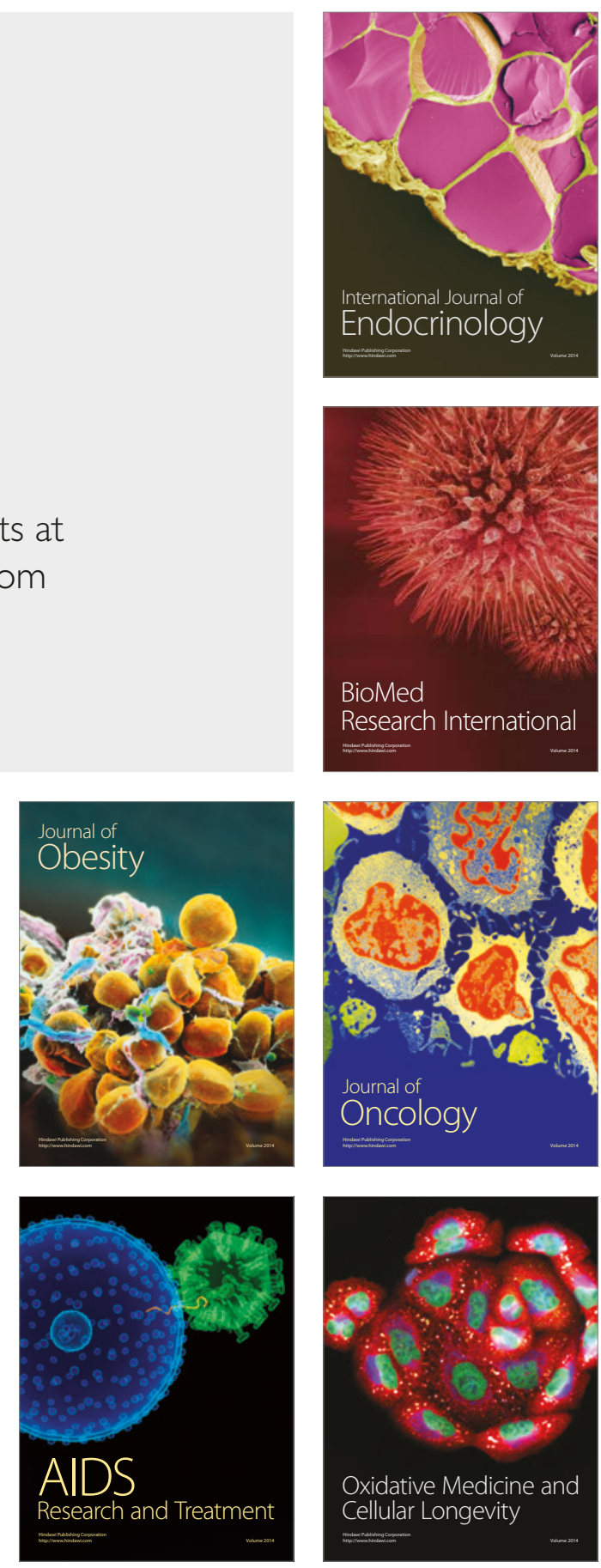